\title{
A Survey of Additive Manufacturing Capabilities
}

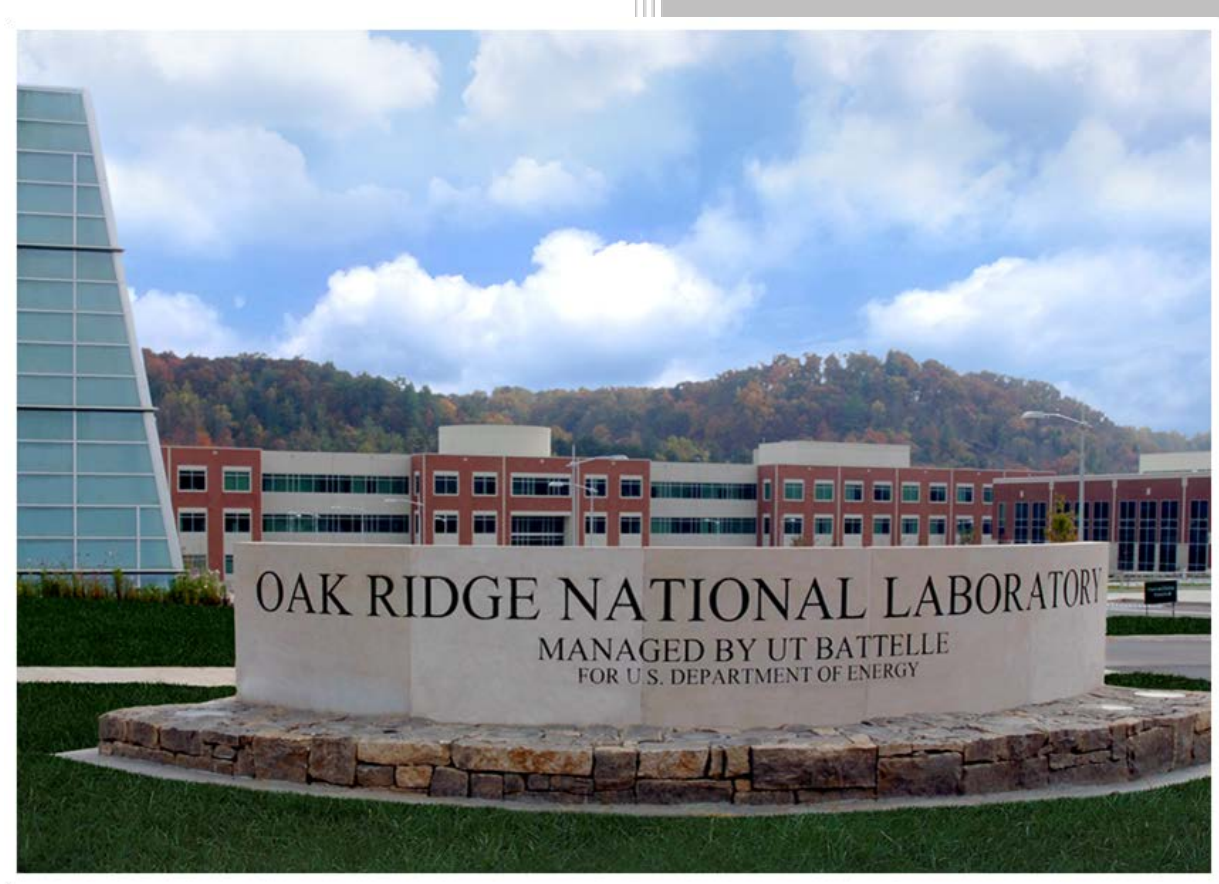

R. J. Belles

W. P. Poore

T. J. Harrison

M. D. Muhlheim

T. R. Muth

Approved for public release.

Distribution is unlimited. 


\section{DOCUMENT AVAILABILITY}

Reports produced after January 1, 1996, are generally available free via US Department of Energy (DOE) SciTech Connect.

Website www.osti.gov

Reports produced before January 1, 1996, may be purchased by members of the public from the following source:

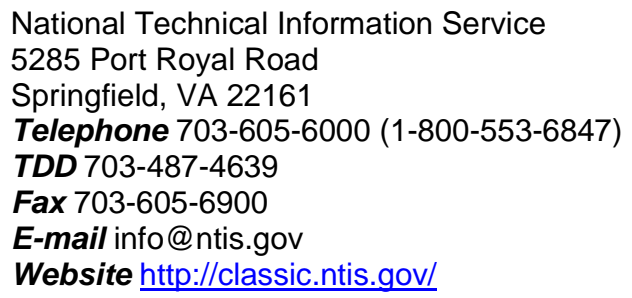

Reports are available to DOE employees, DOE contractors, Energy Technology Data Exchange representatives, and International Nuclear Information System representatives from the following source:

Office of Scientific and Technical Information

PO Box 62

Oak Ridge, TN 37831

Telephone 865-576-8401

Fax 865-576-5728

E-mail reports@osti.gov

Website http://www.osti.gov/contact.html

This report was prepared as an account of work sponsored by an agency of the United States Government. Neither the United States Government nor any agency thereof, nor any of their employees, makes any warranty, express or implied, or assumes any legal liability or responsibility for the accuracy, completeness, or usefulness of any information, apparatus, product, or process disclosed, or represents that its use would not infringe privately owned rights. Reference herein to any specific commercial product, process, or service by trade name, trademark, manufacturer, or otherwise, does not necessarily constitute or imply its endorsement, recommendation, or favoring by the United States Government or any agency thereof. The views and opinions of authors expressed herein do not necessarily state or reflect those of the United States Government or any agency thereof. 


\title{
Reactor and Nuclear Systems Division
}

Metals and Refractories Division

\section{A SURVEY OF ADDITIVE MANUFACTURING CAPABILITIES}

\author{
R. J. Belles \\ W. P. Poore \\ T. J. Harrison \\ M. D. Muhlheim \\ T. R. Muth
}

Date: September 2018

Prepared by

OAK RIDGE NATIONAL LABORATORY

Oak Ridge, TN 37831-6283

managed by

UT-BATTELLE, LLC

for the

US DEPARTMENT OF ENERGY

under contract DE-AC05-00OR22725 



\section{CONTENTS}

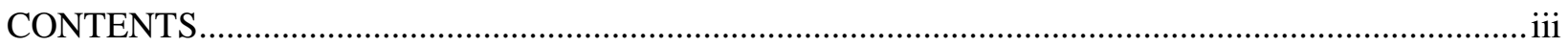

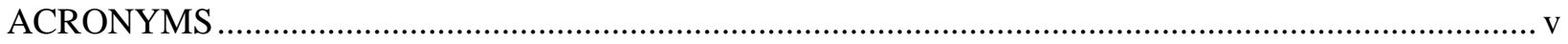

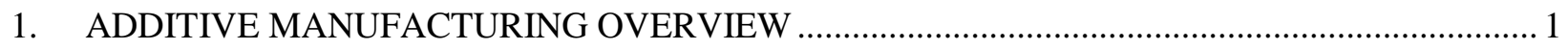

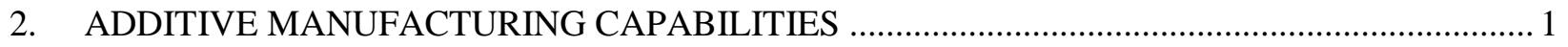

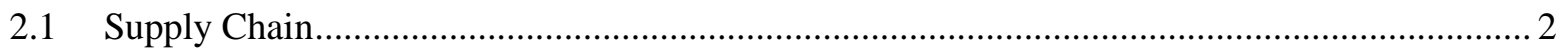

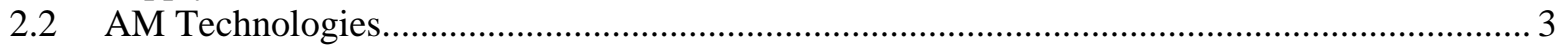

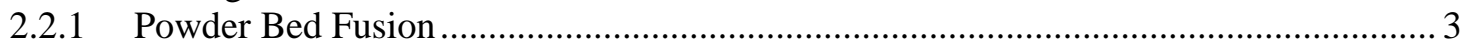

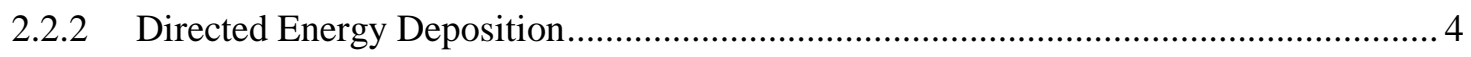

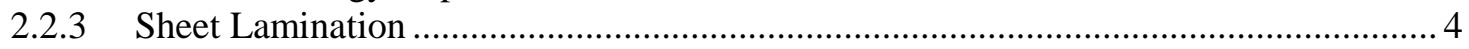

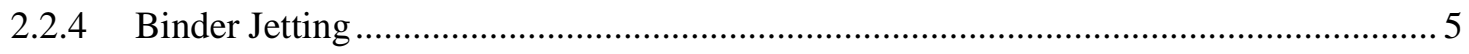

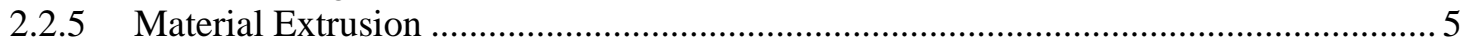

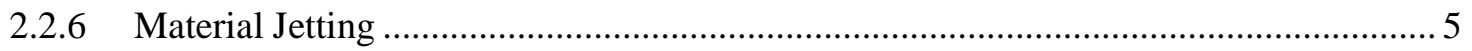

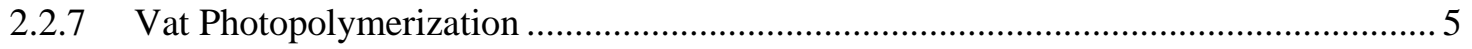

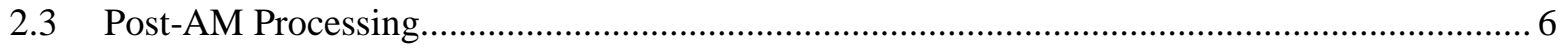

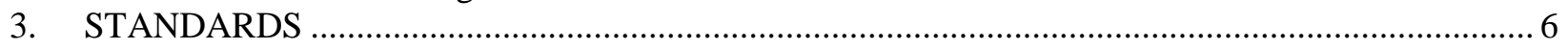

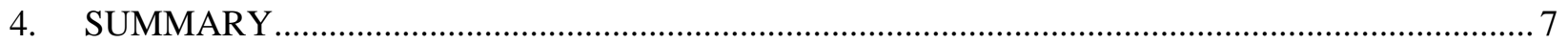

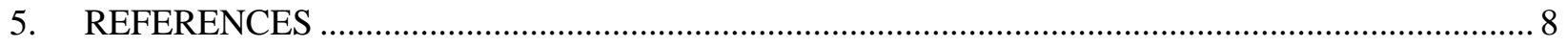





\section{ACRONYMS}

AM

AMSC

ANSI

ASME

ASTM

BPVC

BWR

CAD

DED

DOE

DoD

FAA

FSAR

HIP

LENS

LOM

LWR

NDE

NIST

Non-LWR

NRC

NPP

PBF

PWR

RG

SAE

SDO

SPR

SSC

UAM
Additive manufacturing

Additive Manufacturing Standardization Collaborative

American National Standards Institute

American Society of Mechanical Engineers

American Society for Testing and Materials

Boiler and Pressure Vessel Code

boiling water reactor

computer-aided design

directed energy deposition

US Department of Energy

US Department of Defense

Federal Aviation Administration

final safety analysis report

hot isostatic pressing

laser-engineered net shaping

laminated object manufacturing

light water reactor

non-destructive examination

National Institute of Standards and Technology

non-light water reactor

US Nuclear Regulatory Commission

nuclear power plant

power bed fusion

pressurized water reactor

regulatory guide

Society for Automotive Engineers

standards developing organization

special purpose reactor

systems, structures, and components

ultrasonic additive manufacturing 



\section{ADDITIVE MANUFACTURING OVERVIEW}

Very small special purpose reactors (SPRs) are under consideration by various entities for remote installations and communities. This type of plug-and-go resource requires inherently positive safety attributes and robust design. Such reactors may be transportable with fresh fuel to serve as a complete power "battery," and they may even be transportable on short notice after initial use. SPRs could eliminate costly fossil fuel deliveries. Modifications to regulatory requirements could allow small passively safe reactors to be operated remotely by an offsite operations crew. While use cases for such reactors are currently under development, advanced manufacturing processes should be considered to support reactor economics through more timely and less costly manufacturing of reactor structures and components.

Additive manufacturing (AM) techniques are beginning to provide benefits to numerous industries in terms of reducing cost, weight, waste, etc. The aerospace, defense, medical, and automobile industries are prime examples of industries benefiting from AM. Smaller applications of this technology are beginning to appear in the nuclear industry. SPRs, especially micro-size reactors (e.g., less than $~ 50 \mathrm{MW}$ electric), may benefit from using AM to produce systems, structures, and components (SSCs). This may include production of the fuel, the SSCs in the nuclear island, and other potential applications. For very smallscale reactors, a large portion of the power plant could be produced in a factory using AM techniques and then transported to a fixed or temporary location.

AM offers numerous benefits to the reactor industry. It provides the ability to produce geometries that are difficult or costly to produce with conventional (subtractive machining) methods. AM also provides the ability to produce multiple layers of materials, such as coatings, cladding, or gradients of materials. AM produces components quickly and with minimal waste, and it offers significant reductions in time and infrastructure associated with spare parts management. The potential for improved component capabilities and performance, shorter parts production time, and reduced supply side infrastructure is significant.

A significant advantage of AM is its ability to produce single or small quantities of an item, avoiding the need to develop a significant infrastructure to produce only one or two items. AM supports the innovative nature of micro-reactor development by offering more economic, more timely manufacturing and construction capabilities that can maintain nuclear power as a clean and economic option.

A previous ORNL report [1] focused on early AM material considerations for reactor technologies and provided some initial licensing considerations. The current report is a complement to the previous report, providing a survey of AM capabilities that could be used to manufacture SPR SSCs. Specific reactor use cases and overviews of various reactor types are not included in this report.

It is difficult to be overly detailed regarding availability, testing, and application of specific AM technologies and materials for nuclear use because the AM standards have not kept pace with the capabilities of the rapidly evolving AM industry.

\section{ADDITIVE MANUFACTURING CAPABILITIES}

There are many markets for nuclear reactors, some of which support more small-scale, small market size energy supply applications. As a result, small and remote power applications for clean, reliable nuclear power plants (NPPs) are under consideration. To address the economics of SPRs, vendors must be innovative in their approach to reactor operation and construction to reduce cost while still providing for 
the health and safety of the public and protection of the environment. AM presents a possible path to successful construction.

AM processes build three-dimensional parts by incrementally adding thin layers of materials guided by information loaded into a computer-aided design (CAD) file. The CAD file provides the template for the various AM equipment types to produce complex parts without the need for expensive tooling or forms, and it reduces the need for many conventional processing steps. Intricate parts can be made in one step without the limitations of conventional processing methods and the associated waste. [3]

The chemical compositions of the alloys commonly used in AM differ appreciably. As a result, the differences in thermophysical properties result in significant differences in the structure and the properties of the products fabricated when using different alloys under the same AM processing conditions.

Therefore, all alloys are not equally printable, and an appropriate alloy must be selected to fabricate a defect-free, structurally sound component. During AM, energy absorption by the feedstock materials affects the temperature profiles, deposit geometry, solidification, microstructure and properties of the part. Energy absorption depends on the heat source characteristics. For lasers, electron beams, and plasma arcs, the radius and the power density distribution are important properties of the heat source. [3]

\subsection{SUPPLY CHAIN}

Regardless of the AM process used, a multi-part supply chain is necessary to produce a final component. According to the EWI Additive Manufacturing Consortium [4], a long list of steps is involved to produce a final component:

1. Develop component initial design

2. Produce a CAD file

3. Select component materials

4. Plan the production path

5. Document the thermal history of the materials

6. Evaluate the material residual stress

7. Implement material heat treatment

8. Validate material properties

9. Perform qualification and certification

10. Select the AM process

11. Conduct process sensing

12. Develop process controls

13. Perform component inspection

14. Implement dimensional controls

15. Perform component finishing

16. Document quality assurance

17. Deliver and install component

Several issues must be addressed within the supply chain steps, such as in-process quality control, surface finish, and process repeatability. In addition, economic questions [4] must be addressed prior to using AM techniques to produce any given NPP component. These questions include:

1. Do current manufacturing constraints limit parts performance?

2. Can subcomponents be merged to avoid assembly?

3. Can the number of joints be minimized?

4. Can weight and material be reduced while achieving the same function?

5. Is extensive tooling needed to manufacture a part? 
6. Can new material combinations increase part performance?

7. Can part durability be maximized?

\subsection{AM TECHNOLOGIES}

The American Society for Testing and Materials (ASTM) has categorized AM technologies into seven broad categories:

1. Powder bed fusion (PBF)

2. Directed energy deposition (DED)

3. Sheet lamination

4. Binder jetting

5. Material extrusion

6. Material jetting

7. Vat photopolymerization

Just as every component and material is not an ideal candidate for AM processing, every identified AM technology category is not an ideal choice for producing NPP components.

\subsubsection{Powder Bed Fusion}

AM techniques using PBF employ a laser or an electron beam to melt and fuse powdered material into a shape as directed by a CAD file. PBF is typically used with polymers and metals. Typically, a roller spreads a thin layer of material across the previous layer, and then the material is exposed to a laser or an electron beam, which melts and fuses the powdered material to the previous layer. These steps are repeated as the component is built upward from the base [5].

Other names for this AM technique include:

- Selective layer sintering

- Selective laser melting

- Selective heat sintering

- Direct metal laser sintering

- $\quad$ Electron beam melting

Direct metal laser sintering and electron beam melting are PBF techniques used for metal applications and would be applicable to the production of NPP components. These processes have been used with stainless steel, titanium, cobalt chrome, nickel alloys, and aluminum.

PBF allows multiple parts to be built simultaneously, and it allows complex geometries to be constructed. However, part size is limited by the area of the machine's build chamber. The build rate is typically less than five pounds per hour and is considered slow. It is also noted to be difficult to control the material microstructure, and heat treatment is required post-build [6].

In general, as-deposited AM austenitic stainless steels exhibit higher yield strength, ultimate tensile strength and hardness, and lower ductility when compared to their traditionally processed counterparts. Austenitic stainless steels made using PBF show no clear trend in yield and ultimate tensile strengths as a function of linear or volumetric heat input. The thermal history of the components being fabricated by PBF depends on the scan strategy, which cannot typically be stipulated in closed commercial AM systems and is difficult to capture. Also, scan strategies vary between studies based on the effects of multiple samples being fabricated on the same build plate and the orientation of the samples. The variation in scan 
strategy, as well as any variation in laser spot size or build preheating, is at least partially responsible for the lack of clear trends for PBF austenitic stainless-steel components [3].

\subsubsection{Directed Energy Deposition}

AM techniques using DED typically employ a nozzle mounted on a multi-axis arm, which deposits melted material onto the specified surface, where it solidifies. The process is similar in principle to material extrusion. The build material, which can be deposited from any angle using the multi-axis arm, is melted upon deposition with a laser or electron beam. The process can be used with polymers and ceramics, but it is typically used with metals in the form of either powder or wire. Electron beam versions are only used with metals [5].

Other names for this AM technique include:

- $\quad$ Laser-engineered net shaping (LENS)

- Directed light fabrication

- Direct metal deposition

- 3D laser cladding

DED has been used with titanium and cobalt-chrome alloy. It is considered a good process to use when repairing or adding material to an existing component.

LENS using a powder feed can be used to fabricate larger structures with good microstructure. However, complex geometries are more difficult with this technique, and significant post-build processing is required [6].

Austenitic stainless steels made by DED cause the yield strength and ultimate tensile strength to decrease with increasing linear heat input, but no clear trend is found in yield or ultimate tensile strengths as a function of volumetric heat input. Lower linear heat inputs result in smaller melt pools, higher thermal gradients, and therefore fast cooling rates and fine microstructures, leading to higher yield and ultimate tensile strengths compared to components made with higher linear heat inputs [3].

Ni-base alloys used in AM include Inconel 625, Inconel 718 and Invar 36. Ni-base superalloys Inconel 718 and Inconel 625 are widely used in the aerospace industry due to their high strengths at elevated temperatures. There is no clear trend between ultimate tensile strength and ductility data for Ni-base alloys processed via AM (PBF and DED). Thus, more data are needed to link processing, structure, and properties in these alloys made by AM [3].

\subsubsection{Sheet Lamination}

AM techniques using sheet lamination typically employ layers of material that are bonded together. The two principle techniques for AM sheet lamination include:

- Ultrasonic additive manufacturing (UAM)

- Laminated object manufacturing (LOM)

UAM uses sheets or ribbons of metal which are bound together using ultrasonic welding. The process requires additional machining and removal of the unbound metal. This is often done during the welding process. LOM uses a similar layer-by-layer approach, except, paper is used as material and adhesive instead of welding. Laminated objects are often used for aesthetic and visual models and are not suitable for structural use. UAM uses metals that include aluminum, copper, stainless steel and titanium. The 
process is low temperature and allows for internal geometries to be created. The process can bond different materials and requires relatively little energy, as the metal is not melted [5]. Although metal parts can be manufactured using this AM technique, it does not support the direct production of structural NPP components. UAM is being investigated for fuel and control rods.

\subsubsection{Binder Jetting}

AM techniques using binder jetting process two materials; a powder-based material and a binder. The binder acts as an adhesive between powder layers. The binder is usually in liquid form, and the build material is in powder form. A print head moves horizontally along the $\mathrm{x}$ and $\mathrm{y}$ axes of the machine and deposits alternating layers of the build material and the binding material. After each layer is completed, the machine lowers the build platform including the object being printed, and the next layer is deposited [5].

Binder jetting can be used with stainless steel, polymers, and ceramics. However, due to the method of binding, the material characteristics are not always suitable for structural parts, and despite the relative speed of printing, additional post processing adds significant time to the overall process. Although metal parts can be manufactured using this AM technique, this technique does not support the direct production of structural NPP components. However, irradiation testing of specimens using this process is in progress at the Idaho National Laboratory's Advanced Test Reactor [6].

\subsubsection{Material Extrusion}

AM techniques using material extrusion cause the material to be drawn through a nozzle, where it is heated and then deposited layer by layer. The nozzle can move horizontally, and a platform moves up and down vertically after each new layer is deposited. Material extrusion is used with polymers and plastics [5]. It is a technique commonly used on many inexpensive, domestic, and hobby 3D printers, and it does not support the production of structural NPP components. Polymers and plastics may be used for shielding.

\subsubsection{Material Jetting}

AM techniques using material jetting create objects in a method similar to the method used in a twodimensional ink jet printer. Liquid material is jetted onto a build platform using either a continuous or drop-on-demand approach. Once the material solidifies, more liquid material is applied, and the model is built layer by layer. The material is deposited from a nozzle which moves horizontally across the build platform. The material layers are then cured or hardened using ultraviolet light. Machines vary in complexity and in their methods of controlling the deposition of material. Because material must be deposited in drops, the number of materials available to use is limited. Polymers and waxes are suitable and are commonly used due to their viscous nature and ability to form drops [5]. Therefore, this AM method does not support the production of structural NPP components. Polymers and plastics may be used for shielding.

\subsubsection{Vat Photopolymerization}

AM techniques using vat photopolymerization involve a vat of liquid photopolymer resin. An ultraviolet light is used to cure or harden the resin where required, while a platform moves the object being made downwards into the vat of liquid photopolymer resin after each new layer is cured. Where the resin encounters the light, it cures or hardens. Vat photopolymerization is only used with polymers and plastics [5], so this AM method does not support the production of structural NPP components. Polymers and plastics may be used for shielding. 


\subsection{POST-AM PROCESSING}

Using a laser or an electron beam to manufacture components from a powdered metal or wire subjects the material to repeated heating and cooling. This process typically leads to internal stresses that must be relieved before the component can be removed from the build plate. After the component is removed from the build plate, subsequent heat treatment and controlled cooldown is required to improve material properties such as density and strength. Heat treatment can affect the finished component dimensions as it does in conventionally produced components.

A process frequently used in the metal casting industry in lieu of heat treating the component is hot isostatic pressing (HIP). Using HIP, the component is subjected to high pressure in an inert environment at an elevated soak temperature. This improves material density by eliminating internal voids. HIP also improves fatigue resistance. Because AM manufacturing resembles metal casting, HIP is a frequently used AM post-processing technique.

Surface roughness is currently a major drawback of AM in two important aspects. First, rough surfaces that contact flowing fluids will impact system performance. Second, rough surfaces provide stress concentrations that serve as crack nucleation sites, potentially limiting fatigue performance [3]. Therefore, in nuclear applications, surface finishing is a necessity. Surface finishing can be very complex or impossible to implement on very complex parts with difficult-to-reach internal surfaces. Testing and inspection of each component will also be required. Tight flow specifications may cause components manufactured by AM techniques to fail final testing. Since component dimensions can change during post AM processing, process repeatability is a consideration. Standards for nondestructive examination (NDE) of AM components during processing and post-processing are necessary [7] and should be developed.

\section{STANDARDS}

The growth in the use of AM and the expansion of its techniques and materials creates challenges in specifying, producing, and certifying SSCs for nuclear power reactors. Standards governing the materials, applications, manufacturing, testing, certification, use, etc., for nuclear power applications have not kept pace with growth in the field. Development of AM standards in parallel with the growth in this industry will accelerate its application in the nuclear power field.

Industry consensus standards are frequently endorsed in regulatory guidance issued either by the US Nuclear Regulatory Commission (NRC) or the US Department of Energy (DOE) as a means to demonstrate compliance with regulations and requirements. Industry standards for materials (chemical composition, flowability, density, particle size and distribution, etc.,); manufacturing methods (process control, machine calibration and qualification, material handling, post-processing needs, cybersecurity, etc.,); quality and certification; nondestructive evaluation (data requirements, methods, metrology); and maintenance and repair of the products are needed to provide assurance that the products meet their requirements and collectively ensure the health and safety of the public. The standards are also essential for designers, manufacturers, suppliers, and users to supply proven products to accelerate the adoption of new nuclear technologies.

In 2016, America Makes, the national accelerator for AM and 3D printing, along with the American National Standards Institute (ANSI) launched the America Makes \& ANSI Additive Manufacturing Standardization Collaborative (AMSC) "to coordinate and accelerate the development of industry-wide AM standards and specifications consistent with stakeholder needs and thereby facilitate the growth of the AM industry” [2]. AMSC does not write standards, nor does ANSI. (ANSI serves as administrator and 
coordinator of the US private-sector voluntary standardization system to help define standardization needs and is engaged in accreditation of standards development organizations.)

The need was recognized to develop an AM standards development roadmap. AMSC is leading a program to identify AM standards and specifications that are in use or being developed. Federal agencies, including the National Institute of Standards and Technology (NIST), the Department of Defense (DoD), the Federal Aviation Administration (FAA), and several more standards development organizations (SDOs) are participating in this collaborative effort. Even so, the development of new consensus standards and their endorsement by NRC or DOE can be a lengthy process.

\section{SUMMARY}

Of the AM capabilities reviewed in this report, PBF and DED are the two AM techniques that most readily lend themselves to the production of structural parts, including components for NPPs. The questions posed in Section 2.1 must be considered for each proposed NPP SSC to be produced using AM techniques. Steels with good yield strength characteristics can be produced using AM methods. However, fatigue, which is the mechanical response of a material subjected to cyclic loading, becomes an issue. In a material completely free of porosity or surface-related defects, fatigue failure occurs in a catastrophic manner when voids form due to the accumulation of dislocations. These propagate outward until complete fracture occurs. When stress concentrators such as surface or internal defects are introduced, the number of cycles required for fracture of a specimen can be greatly reduced, thus decreasing fatigue life [3].

Creep properties may also differ between components produced by AM techniques and components produced by traditional means. Creep in processed parts is due to the presence of defects and fine microstructural features [3]. Post AM heat and pressure treatment of components can relieve some creep behavior in the metal. However, more testing and irradiation performance will be necessary for nuclear component applications.

DOE has an initiative underway to provide irradiation data. Irradiation testing specimens ${ }^{1}$ of stainless steel alloy 316L and Inconel 718 produced using AM processes have been conducted at the Advanced Test Reactor at Idaho National Laboratory. The irradiated specimens used in the DOE reactor material AM initiative were produced using PBF and DED techniques. Larger components produced using AM techniques with post-processing provided using HIP are planned for irradiation testing in the Advanced Test Reactor. These components include a large alloy 316L valve body, a boiling water reactor (BWR) steam separator inlet swirler, and a BWR nozzle [6].

\footnotetext{
${ }^{1}$ It is important to note that alloy 316L and Inconel 718 are designations for wrought alloys, which are ductile enough to be worked hot or cold during fabrication. However, AM is not a wrought process - it is a melting and solidification process. AM metals are more like cast-metal alloys. Metal casting is characterized by molten metal flowing into a mold by gravity or into a die by high pressure to create a shape. Therefore, the melting and solidification that occurs during AM is like casting. There is no deformation processing in typical AM. Cast Alloy CF8M is the approximate equivalent of wrought Alloy 316L.
} 
In the paper on AM manufacturing of metallic components [3], the authors succinctly summarize the state of the art:

Although mechanical properties of parts produced by AM are in many cases comparable with their conventionally processed counterparts, properties can vary with process parameters and locally within a part. Controlling mechanical properties of parts will require greater understanding of both the AM process and the evolution of microstructure under complex thermal cycles. Progress in better understanding the AM processes will be important to avoid common defects and to ultimately tailor composition, structure and properties of AM parts based on scientific principles.

Furthermore, greater market penetration of AM will require an increased level of standardization and control to attain repeatable processes to produce parts with consistent properties.

Developing nuclear-related industry standards in parallel with development of AM materials and manufacturing methods, as well as means of product testing and validation, will accelerate the adoption of new nuclear technologies.

\section{REFERENCES}

1. R. J. Belles et. al., A Survey of Materials for Additive Manufacturing, ORNL/TM-2018/886, ORNL, Oak Ridge, TN, June 2018.

2. America Makes \& ANSI Additive Manufacturing Standardization Collaborative (AMSC), Standardization Roadmap for Additive Manufacturing, Version 2.0, Preliminary Draft, April 6, 2018, https://share.ansi.org/Shared\%20Documents/Standards\%20Activities/AMSC/AMSC_18001_PRELIMINARY_FINAL_DRAFT_AMSC_Roadmap_v2.pdf

3. T. DebRoy et al., Additive Manufacturing of Metallic Components - Process, Structure, and Properties, Progress in Materials Science 92, pp 112-234, 2018.

4. F. Medina, Selecting the Correct Material and Technology for Metal AM Applications, EWI Additive Manufacturing Consortium, NRC Public Meeting, Bethesda, MD, November 28-29, 2017.

5. Additive Manufacturing Research Group, Loughborough University, http://www.lboro.ac.uk/research/amrg/, Accessed August 31, 2018.

6. A. Hahn, Additive Manufacturing Initiatives, DOE-NE, NRC Public Meeting, Bethesda, MD, November 28-29, 2017.

7. J. Waller, NDE and Inspection Challenges for Additively Manufactured Components, NASA, NRC Public Meeting, Bethesda, MD, November 28-29, 2017. 